\title{
Solvent Effect on the Morphology of Lamellar Nanocomposites Based on HIPS
}

\author{
Paulo Sergio Rangel Cruz da Silva*, Maria Inês Bruno Tavares ${ }^{a}$ \\ ${ }^{a}$ Centro de Tecnologia, Instituto de Macromoléculas Professora Eloisa Mano - IMA, \\ Universidade Federal do Rio de Janeiro - UFRJ, Bloco J, Ilha do Fundão, CP 68525, \\ CEP 21945-970, Rio de Janeiro, RJ, Brazil
}

Received: July 6, 2014; Revised: January 26, 2015

In this study, hybrid nanocomposites based on HIPS, high-impact polystyrene, were prepared in chloroform and in a 1:1 mixture of toluene and chloroform varying the quantity of organophilic montmorillonite. The morphology of the hybrid materials was investigated by X-ray diffraction (XRD) and proton relaxometry, determined in a low-field ${ }^{1} \mathrm{H}$ nuclear magnetic resonance (NMR). The thermal characteristics were also obtained through thermogravimetric analysis. The emphasis of this study was to compare the effect of a pair of solvents against a single solvent in the formation/ organization of the nanostructured materials when the solution method is applied. It was taken into consideration Interactions involving polymer-solvent, nanoparticle-solvent, and, principally, polymernanoparticle-solvent. The results show that the choice of solvent affects greatly the characteristic of the nanocomposites. Nanocomposites prepared with chloroform/toluene were more homogenous, more prone to exfoliate (for all organoclay concentrations), and had higher degradation temperature compared to the materials obtained with chloroform. It is clear from the data that the use of a solvent pair is important to produce good nanocomposites when using the solution method and that the clay proportion plays a role in the dispersion of organoclay in the polymer matrix.

Keywords: polymer, nanocomposites, $H I P S, N M R$, relaxometry

\section{Introduction}

Polymer nanocomposites have revolutionized polymer science due to the broad range of applications. The high surface area and nano sized dimension provide improved characteristics to materials containing nanoparticles. These improvements happen only if good dispersion is obtained. In the solution method, the ability of choosing the proper solvent is crucial to obtain samples with good dispersion. Therefore, it is necessary to evaluate the impact of a given solvent or of a solvent pair in the preparation of polymer nanocomposites ${ }^{1,2,3}$. It is known that in solution method the solvent can affect the morphology of nanocomposites based on the different Hildebrand/Hansen solubility parameters ${ }^{4}$. Thus, many aspects must be taken into consideration when solution method is used to obtain the nanocomposites, including polymer-solvent interaction; time and temperature of solubilization; and stability of the solution or dispersion.

A common solvent used to solubilize high-impact polystyrene (HIPS) is chloroform, which has the advantage of low price and easy recovery. It is also known that toluene is a better solvent than chloroform for butadiene. Since polymer-solvent interaction is important to obtain materials from solution casting method, it is reasonable to assume that a mixture of solvents should improve the solubility of this kind of polymer ${ }^{5,6}$. Based on these arguments, we were curious to look at the behavior of a 1:1 mixture of toluene and chloroform for the HIPS systems compared to chloroform alone.

*e-mail: rangel@ima.ufrj.br
Montmorillonite is often used in the preparation of hybrid materials, not only because of its low cost compared to other additives, but also because it promotes significant changes in matrix properties, such as anti-flammability property, water barrier, and gas barrier ${ }^{7}$. In order to improve the clay compatibility with the matrix, it is necessary to modify the clay with quaternary ammonium salt, which promotes affinity with organic polymers as the surfactant can aid induce intercalation and clay lamellae exfoliation, generating different nanomaterials morphologies and, consequently, different properties ${ }^{8,9,10}$. Foster showed that each solvent can promote different degrees of swelling in the clay galleries, which was also demonstrated in Queroz et al. work ${ }^{11}$. The swelling can help the intercalation and exfoliation process of the clay layers in the polymer matrix, thus forming polymer nanocomposites. It is known that each clay nanostructure presents different properties; generally the intercalation structure may improve the impact property and exfoliation structure may improve the water barrier and gas barrier property and also anti-flammability characteristics $^{12,11}$

Various characterization techniques are used to evaluate the characteristics of these new materials. X-ray diffraction (XRD) is normally used to measure the interlayer distance through the changes in the peaks located in the $d_{001}$ plane. If this peak is shifted to lower values, the new material will probably have a predominant intercalated morphology; while if the peak disappears, the predominant morphology could be the exfoliated ${ }^{13,14}$. 
Nuclear magnetic resonance (NMR) relaxometry, through the measurement of spin-lattice relaxation time, has being used to identify the heterogeneity of polymer materials containing domains with size ranging from $\sim 25$ to $>50 \mathrm{~nm}^{15}$. The relaxation time parameter with a time constant, $T_{1}$, provides information on the polymer systems homogeneity and miscibility; and also the domain size of phases formed according to the generated morphology in the polymer system, it was very much used to evaluate the molecular dynamics of polymer blends ${ }^{16}$. The proton spin-lattice relaxation time is a parameter that is sensitive to fast movements of chains. Any change in the molecular dynamic causes changes in the values of relaxation time. This feature makes the relaxation time a good tool to analyze the molecular dynamics of polymer systems and materials, especially nanocomposites morphology. The determination of relaxation time of nanomaterials, containing clay as nanoparticle, can give clues of the clay lamellae organization. When the clay lamellae are well dispersed and distributed in the polymer matrix, at least two main morphologies can be formed, exfoliated and intercalated. In most cases, a combination of both morphologies is found in nanostructured materials ${ }^{17}$. If the exfoliation process is predominant, the value of relaxation time normally decreases compared to the polymer itself. This occurs due to the influence of the free movement of the polymer chains around the clay lamellae and also because of the paramagnetic metals present in the structural organization of clay lamellae (e.g. iron). This paramagnetic metals act as relaxing agents contributing to decrease of relaxation times. The increase in the relaxation time values means that the polymer chains are constrained between the clay lamellae, which causes a restriction in their molecular movements, leading to the formation of a predominantly intercalated morphology $y^{18,14}$.

Thus, the main objective of the present study is to compare the morphology of the hybrids films based on HIPS/OMMT prepared using the pair of solvent (toluene and chloroform in 1:1 proportion) and only chloroform, obtaining by solution casting method. The second one is evaluate the hybrid materials mainly by NMR relaxometry, through proton spin-lattice relaxation data. The scientific importance of this study is related to the fact that the new material must be a homogeneous nanostructured one, and the solvent chosen is the most important fact to obtain materials by solution cast method. Beside this NMR relaxometry is a good alternative technique to evaluate the behavior of nanomaterials, because it is a non-destructive, rapid, reproducible, low cost and sensitive method.

\section{Experimental}

\subsection{Materials}

In this work commercial organically montmorillonite modified with dimethyl benzyl hydrogenated tallow ammonium (DMBHTA) was purchased from Bentec. High-impact polystyrene in pellet form was purchased from Innova S.A.. Chloroform and toluene was received from Tedia Brazil.

\subsection{Nanocomposite preparation}

To obtain each hybrid material, $10 \mathrm{~g}$ of polymer was initially dissolved in $200 \mathrm{~mL}$ of chloroform or 1:1 chloroform/toluene mixture by mechanical stirring for 24 hours. In parallel, the clay mass (1,2 and 3\% w/w) was dispersed in $50 \mathrm{~mL}$ of chloroform by magnetic stirring for 24 hours. After that period, the clay dispersions were poured into the polymer solutions and stirred for 24 hours, when a homogeneous mixture was obtained. This was then poured into petri dishes ( $150 \mathrm{~mm}$ diameter). The dishes were dried in an oven at $\sim 40^{\circ} \mathrm{C}$ for 24 hours to remove the solvent(s), leaving a film coat on the dishes.

\subsection{X-ray analysis}

The XRD measurements were performed using a Rigaku diffractometer with $\mathrm{CuK} \alpha$ radiation $(\lambda=0.154 \mathrm{~nm}, 40 \mathrm{Kv}$, $120 \mathrm{~mA}$ ) at room temperature, scanning over the $2 \theta$ range from $2^{\circ}$ to $30^{\circ}$ in $0.05^{\circ}$ steps, at a rate of $1^{\circ} / \mathrm{min}$.

\subsection{Thermogravimetric analysis (TGA)}

The thermal degradation temperature and the profile of degradation of the nanocomposites were obtained using a TA Instruments thermogravimetric analyzer. The measurements were carried out under constant nitrogen flow with a heating rate of $10^{\circ} \mathrm{C} / \mathrm{min}$, varying from 30 to $700{ }^{\circ} \mathrm{C}$.

\subsection{NMR relaxometry measurements}

The ${ }^{1} \mathrm{H}$ NMR relaxation data were measured in a lowfield NMR and they were performed using a Maran Ultra $23 \mathrm{NMR}$ analyzer, operating at $23.4 \mathrm{MHz}$ (for protons) and equipped with an $18-\mathrm{mm}$ variable temperature probe operating at $300 \mathrm{~K}$. Proton spin-lattice relaxation time $\left(\mathrm{T}_{1} \mathrm{H}\right)$ was measured with the inversion-recovery pulse sequence (recycle delay $-180^{\circ}-\tau-90^{\circ}$ - acquisition), using a recycle delay value $5 \mathrm{~T}_{1}$ with a $90^{\circ}$ pulse of $7.5 \mathrm{~ms}$, calibrated automatically by the instrument's software. The amplitude of the FID was sampled for $20 \tau$ data points, ranging from 0.1 to $10,000 \mathrm{~ms}$, with 4 scans each point.

\section{Results and Discussion}

The hybrid materials were first submitted to XRD and thermogravimetric analyzes to evaluate the clay morphologies in the matrix and the influence of the morphology in the thermo degradation process, respectively.

\subsection{X-ray diffraction}

The XRD pattern displayed basal spacing $\mathrm{d}_{001}$ of clay and amorphous halo of HIPS (Figure 1) ${ }^{19}$. The materials prepared with chloroform (HC) displayed different diffraction behavior according to the clay ratio. $\mathrm{HC} 1$ sample showed two types of morphology; the fist one is intercalated structure with a peak located at 3.15 theta degree and the second one is some agglomeration of clay particles located at 5.1 theta degree, which is in the same position as the clay itself.

The nanocomposites prepared with the solvent mixture (HCT) indicated that the clay was dispersed with a better distribution than the HIPS sample obtained in chloroform as solvent. This is evident by the absence of the $d_{001}$ clay peak located at 5.1 theta degrees, present in the HC samples, 


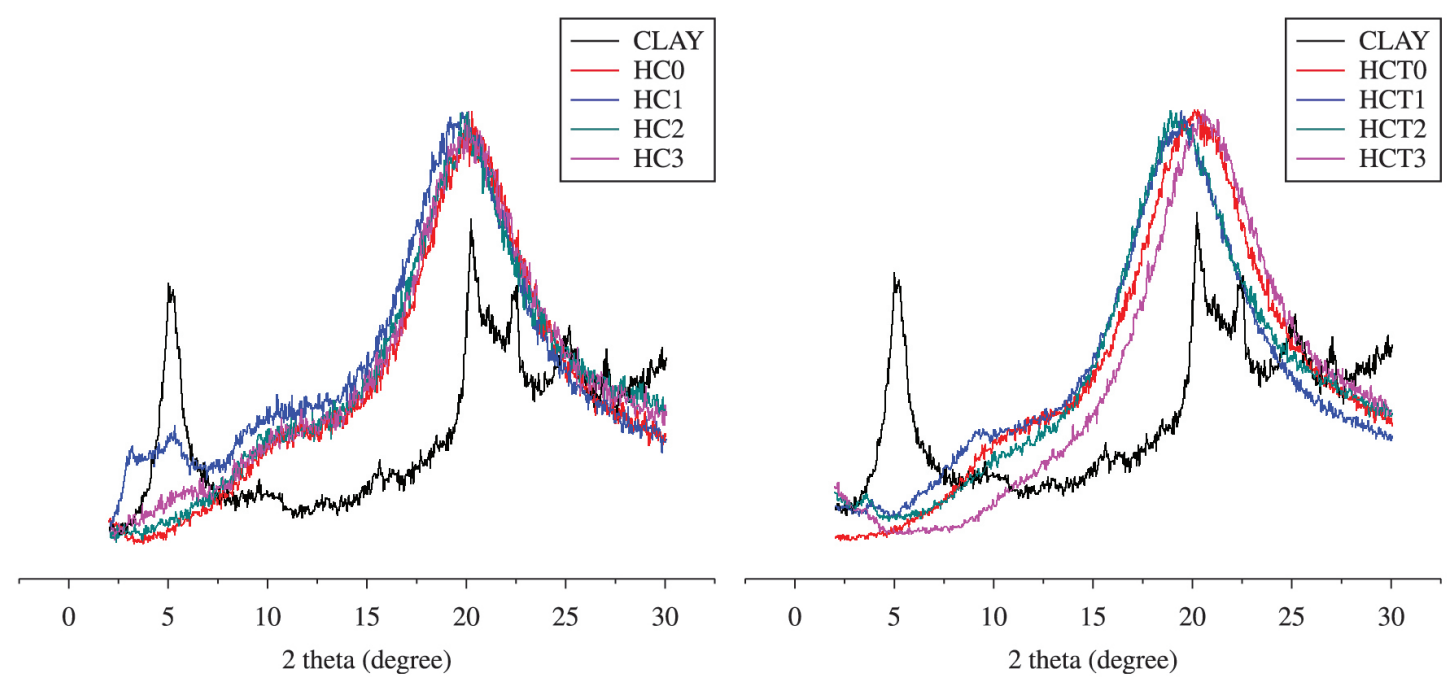

Figure 1. The X-ray diffractograms of clay and nanomaterials with HIPS samples prepared with chloroform (HC) and chloroform/ toluene (HCT).

indicating change in the interlayer spacing of the clay. However, HCT2 showed a small peak located around 3 theta degrees, showing that at this proportion a mix of intercalated and exfoliated structure is present with predominance of exfoliation. For all other compositions wasn't detected the peak relating to the interlayer spacing of the clay.

These results suggest that the pair of solvent is more effective than chloroform alone for the preparation of the hybrid materials.

\subsection{TGA measurements}

Table 1 lists the degradation temperatures obtained for all samples. The TG values indicate that the samples prepared with mixed solvents showed higher degradation temperatures compared to the samples prepared with chloroform alone, pointing to a better performance of the former. They also displayed a better solubilization pattern, which induced the formation of systems with different morphology, associated with the difference in intermolecular strength forces. However, it was found that at $3 \%$ of organoclay both solvent systems displayed the same behavior, implying that at this proportion the organoclay amount plays a more important role than the solvent type.

\subsection{NMR relaxometry data}

The values of proton spin-lattice relaxation time are listed in Table 2 for both solvent systems.

From these results it can be seen that the values of the relaxation times for the HCT samples are higher than those of the HC samples, suggesting that the pair of solvents promoted changes in the nanostructure of the matrix, making it more rigid. This can be attributed to the dispersion force of the solvent, which is the principal factor interfering with the organoclay dispersion and distribution. This statement is in agreement with the work developed by Ho \& Glinka ${ }^{4}$.

Another important information extracted from these data is related to the type of structure (intercalated or exfoliated) formed in the material as a function of the solvent and the organoclay composition used. The decrease
Table 1. TG degradation data for the samples prepared with chloroform (HC) and chloroform/toluene (HCT).

\begin{tabular}{ccc}
\hline \multirow{2}{*}{ Clay (\%) } & \multicolumn{2}{c}{ Degradation Temperature $\left( \pm \mathbf{1}^{\circ} \mathbf{C}\right)$} \\
\cline { 2 - 3 } & HC & HCT \\
\hline 0 & 428 & 432 \\
1 & 436 & 445 \\
2 & 438 & 444 \\
3 & 442 & 441 \\
\hline
\end{tabular}

Table 2. Values of proton spin-lattice relaxation times for the samples prepared with chloroform (HC) and chloroform/toluene (HCT)

\begin{tabular}{ccc}
\hline Clay $(\%)$ & ${ }^{1} \mathbf{H}$ spin-lattice relaxation times $-\mathbf{T}_{\mathbf{1}}(\mathbf{m s})(\mathbf{\pm 2} \boldsymbol{\%})$ \\
\cline { 2 - 3 } & HC & HCT \\
\hline 0 & 504 & 570 \\
1 & 503 & 540 \\
2 & 434 & 519 \\
3 & 468 & 513 \\
\hline
\end{tabular}

in proton relaxation values suggests that the nanocomposites obtained with $\mathrm{HC}$ have perhaps a more predominant exfoliated structure, except for the sample containing $1 \%$ of organoclay which seems to have a more predominant intercalated structure, since its relaxation time was similar to the polymer. This occurs when the restriction of movement of the polymer chains among the clay lamellae is stronger than the effect of paramagnetic metals in the clay lamellae structure. However, the decrease in relaxation time in the $\mathrm{HC}$ sample containing $2 \%$ of organoclay strongly suggests a higher degree of exfoliated structure, since the polymer chains are closer to the paramagnetic metals after clay exfoliation process. Interestingly, in the case of the $\mathrm{HC}$ samples containing $3 \%$ of organoclay, an increase in relaxation data was observed, when compared with the $2 \%$ clay, indicating that the exfoliation happened to a lesser extent. 

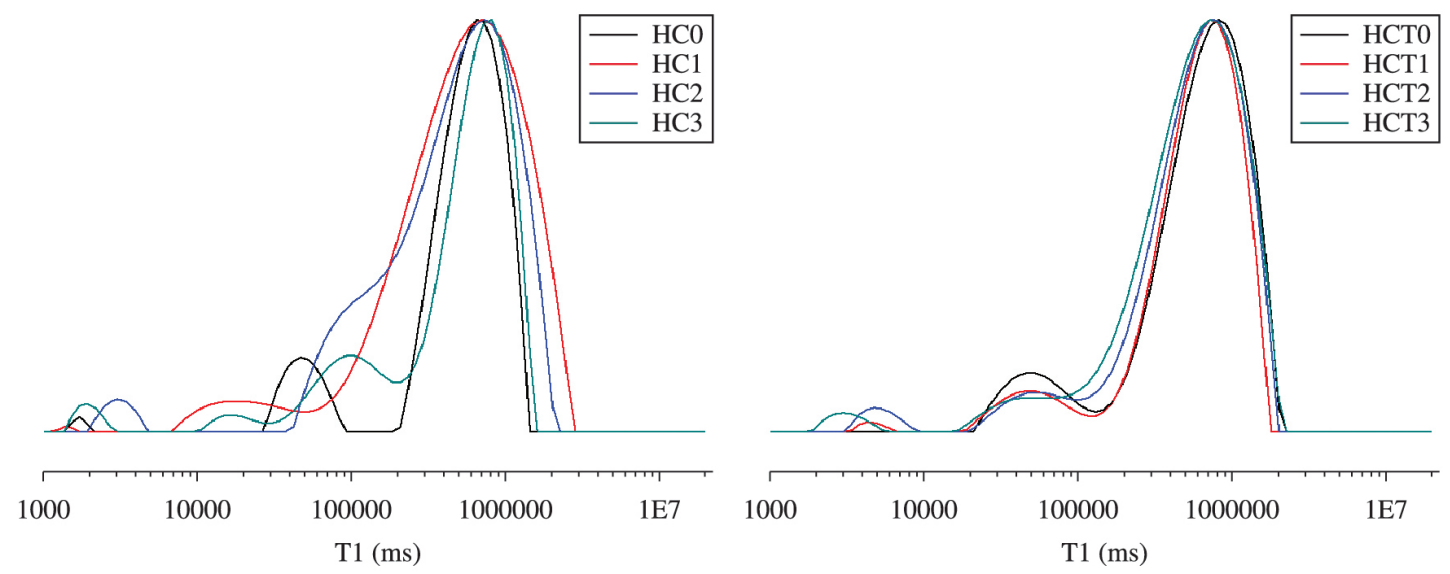

Figure 2. Domains curves distribution for the samples prepared with chloroform (HC) and chloroform/toluene (HCT)

The relaxation time behavior for HCT samples is different when compared with HC samples. For all ratios of organoclay it was observed a decrease in $\mathrm{T}_{1}$, which shows that for HCT samples the predominance is an exfoliated structure. The decrease is more pronounced for 2 and $3 \%$ of organoclay; showing that a good dispersion and distribution of organoclay took place with the use of a pair of solvents.

These results support that the use of a pair of solvents improved the solubilization of the polymer helping the dispersion of the nanoparticles and promoting a morphology containing exfoliated clay lamellae. This behavior are in agreement with the data observed by $\mathrm{Xu}$ et al. ${ }^{20}$.

The domains curves distribution of proton spin-lattice relaxation for the samples prepared with chloroform (HC) and chloroform/toluene (HCT) with are shown in Figure 2.

Analyzing the profile of the relaxation domain curves, we can see that $\mathrm{HC} 1$ and $\mathrm{HC} 2$ have an enlargement of the domain base, showing that a mix of nanostructures was formed, probably containing part exfoliated and part intercalated structures. $\mathrm{HC} 3$ seems to be more homogenous, presenting a narrow domain base, as a consequence of less domains distribution anisotropy. This behavior was not observed in the HCT samples. The domain curves of the HCT films showed that the solvent mixture is more effective in breaking the interaction forces between polymer-polymer

\section{References}

1. Bayram I, Oral A and Kamil F. Synthesis of poly (cyclohexene oxide) -montmorillonite nanocomposite via in situ photoinitiated cationic polymerization with bifunctional clay. Journal of Chemistry. 2013; 2013:1-6. http://dx.doi. org/10.1155/2013/617498.

2. American Society for Testing and Materials - ASTM. Committee E56 on Nanotechnology. ASTM E2456-06: standard terminology for nanotechnology. West Conshohocken; 2012. p. 1-4.

3. Kumar V and Singh A. Polypropylene clay nanocomposites. Reviews in Chemical Engineering. 2013; 29(6):439-448. http:// dx.doi.org/10.1515/revce-2013-0014. and clay-clay, as well as in promoting better nanoparticles dispersion and distribution in the polymer matrix. In summary, the synergy of chloroform and toluene is reflected in the homogeneity of the HCT samples, confirming that the nanomaterials obtained display good dispersion and distribution.

\section{Conclusion}

Different solvents can induce different results in the same system. The nanocomposites prepared with chloroform/toluene were more homogenous, more prone to exfoliate (for all organoclay concentrations), and had higher degradation temperature compared to the materials obtained with chloroform. It is clear from the data that the use of a solvent pair is important to produce good nanocomposites when using the solution method and that the clay proportion plays a role in the dispersion of organoclay in the polymer matrix. The results showed that the use of a pair of solvents is important to produce good nanocomposites by the solution method.

\section{Acknowledgments}

The authors are gratefully for CNPq, CAPES, FAPERJ and Petrobras, for financial support of this work.

4. Ho DL and Glinka CJ. Effects of solvent solubility parameters on organoclay dispersions. Chemistry of Materials. 2003; 15(6):1309-1312. http://dx.doi.org/10.1021/cm0217194.

5. Silva PSRC and Tavares MIB. Intercalação por solução de poliestireno de alto impacto em montmorilonita organofílica obtenção e caracterização. Polímeros Ciência e Tecnologia, 2013; 23(5):644-648. http://dx.doi.org/10.4322/ polimeros.2013.047.

6. Zhou Q, Li B-G, Jie S and Zheng N. Solvent effect on cis-1,4-specific polymerization of 1,3-butadiene with $\mathrm{CoCl2}(\mathrm{PRPh} 2) 2-\mathrm{EASC}$ catalytic systems. Catalysis Science \& Technology. 2014; 4(3):773-779. http://dx.doi.org/10.1039/ c3cy00634d. 
7. Chimanowsky Junior JP, Soares IL, Luetkmeyer L and Tavares MIB. Preparation of high-impact polystyrene nanocomposites with organoclay by melt intercalation and characterization by low-field nuclear magnetic resonance. Chemical Engineering and Processing: Process Intensification. 2014; 77:66-76. http:// dx.doi.org/10.1016/j.cep.2013.11.012.

8. Huskić M, Žigon M and Ivanković M. Comparison of the properties of clay polymer nanocomposites prepared by montmorillonite modified by silane and by quaternary ammonium salts. Applied Clay Science. 2013; 85:109-115. http://dx.doi.org/10.1016/j.clay.2013.09.004.

9. Seyidoglu T. and Yilmazer U. Modification and characterization of bentonite with quaternary ammonium and phosphonium salts and its use in polypropylene nanocomposites. Journal of Thermoplastic Composite Materials. 2015; 28(1):86-110. http://dx.doi.org/10.1177/0892705713486123.

10. Wildan MW and Mohd Ishak Za. Preparation and Properties of Clay-Reinforced Epoxy Nanocomposites. International Journal of Polymer Science. 2013; 2013:1-7. http://dx.doi. org/10.1155/2013/690675.

11. Queiroz MB, Rodrigues SCG, Laborde HM and Rodrigues MGF. Swelling of Brazilian organoclays in some solvents with application in the petroleum industry. Materials Science Forum. 2010; 660-661:1031-1036.

12. Delbem MF, Valera TS, Valenzuela-Diaz FR and Demarquette NR. Modification of a Brazilian smectite clay with different quaternary ammonium salts. Quimica Nova. 2010; 33(2):309315. http://dx.doi.org/10.1590/S0100-40422010000200015.

13. Abolhasani MM, Naebe M, Jalali-Arani A and Guo Q. Influence of miscibility phenomenon on crystalline polymorph transition in poly(vinylidene fluoride)/acrylic rubber/clay nanocomposite hybrid. PLoS ONE. 2014; 9(2):e88715. http:// dx.doi.org/10.1371/journal.pone.0088715. PMid:24551141
14. Monteiro MSDSDB, Cucinelli Neto RP, Santos ICS, Silva EO and Tavares MIB. Inorganic-organic hybrids based on poly ( $\varepsilon$-Caprolactone) and silica oxide and characterization by relaxometry applying low-field NMR. Materials Research. 2012; 15(6):825-832. http://dx.doi.org/10.1590/S151614392012005000121.

15. Silva MA, Tavares MIB, Nascimento SAM and Rodrigues EJR. Caracterização de nanocompósitos de poliuretano/ montmorilonita organofílica por RMN de baixo campo. Polímeros. 2012; 22(5):481-485. http://dx.doi.org/10.1590/ S0104-14282012005000064.

16. Simielli ER. Principais características das blendas poliméricas fabricadas no Brasil. Polímeros Ciência e Tecnologia. 1993; $3(1): 45-49$.

17. Rzayev ZMO. Functional Copolymer/Organo-MMT Nanoarchitectures. VIII. Synthesis, Morphology and Thermal Behavior of Poly(maleic anhydride-alt-acrylamide)-OrganoMMT Clays Nanohybrids. Engineering. 2011; 03(01):73-82. http://dx.doi.org/10.4236/eng.2011.31009.

18. Vanderhart DL, Asano A and Gilman JW. Solid-state NMR investigation of paramagnetic nylon- 6 clay nanocomposites. 2. Measurement of clay dispersion, crystal stratification, and stability of organic modifiers. Chemistry of Materials. 2001; 13(10):3796-3809. http://dx.doi.org/10.1021/cm011078x.

19. Longo S, Mauro M, Daniel C, Galimberti M and Guerra G. Clay exfoliation and polymer/clay aerogels by supercritical carbon dioxide. Frontiers in Chemistry. 2013; 1:28. http:// dx.doi.org/10.3389/fchem.2013.00028.</jrn>.

20. Xu B, Leisen J and Beckham HW. Nanoparticle dispersion in polymer nanocomposites by spin-diffusion-averaged paramagnetic enhanced NMR relaxometry. Nanoscale. 2014; 6(3):1318-1322. http://dx.doi.org/10.1039/c3nr04570f. PMid:24352634 